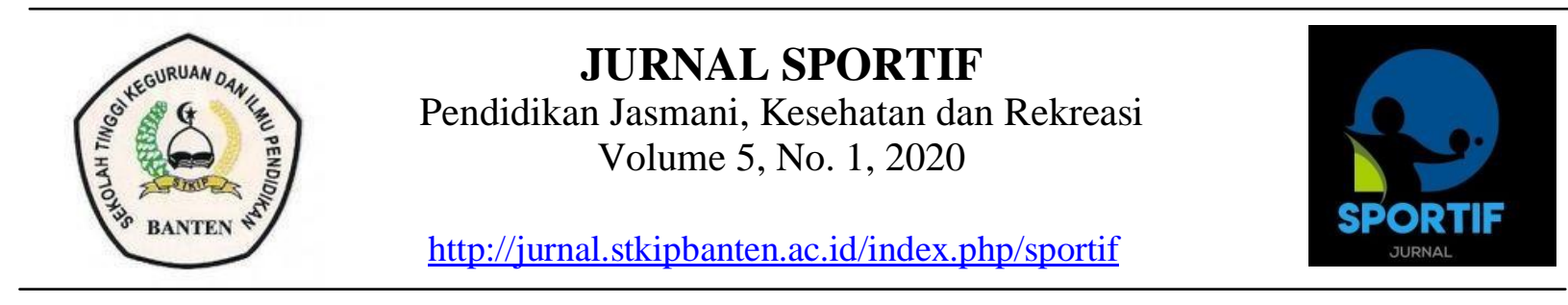

\title{
PENGGUNAAN METODE PUSH UP DALAM PENINGKATAN KEKUATAN SMASH DALAM PERMAINAN BOLA VOLI
}

\author{
Dede Sumarna ${ }^{1}$, Muhamad Al Imron ${ }^{2}$ \\ ${ }^{1}$ Sekolah Tinggi Keguruan dan Ilmu Pendidikan Banten \\ ${ }^{2}$ Mahasiswa Pendidikan Jasmani kesehatan dan Rekreasi

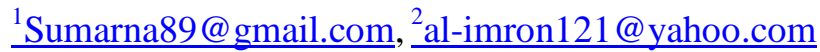

\begin{abstract}
ABSTRAK
Tujuan dari penelitian ini adalah untutk mengetahui Penggunaan Metode Push Up Dalam Peningkatan Kekuatan Smash Dalam Permainan Bola Voli. Motode yang digunakan dalam penelitian ini adalah metode literature yaitu merupakan cara pengumpulan data dengan cara data Primer dan Skunder. Instrumen yang digunakan dalam penelitian ini adalah data Primer yaitu data-data yang diambil dari buku-buku dan sedangkan data Skunder adalah data yang dapat menjelaskan tentang penelitian yaitu skripsi, jurnal dan dokumen hasil seminar. Berdasarkan hasil analisis dan pembahasan yang sudah diuraikan dapat disimpulkan bahwa Data A1 menyimpulkan ada pengaruh latihan push-up standar terhadap keakuratan smash siswa pada permainan bola voli, Data A2 menyimpulkan tingkat kekuatan otot lengan pada siswa ekstrakurikuler memiliki tingkat kekuatan otot lengan pada kategori cukup yaitu dengan ratarata 13,46 dan tingkat keterampilan smash siswa ekstrakurikuler memiliki tingkat keterampilan smash pada kategori baik yaitu dengan rata-rata 18,33, Data A3 menyimpulkan bahwa latihan push- up dapat meningkatkan ketepatan smash pada pemain bola voli Club Sigma Palu. Materi latihan push -up dapat berpengaruh terhadap ketepatan smsah dalam permainan bola voli, karena materi latihan yang diberikan pada pelaksanaan penelitiaan memenuhi atau sesuai dengan prinsip-prinsip latihan. Maka dari itu dengan penggunaan Metode Push Up Dalam Peningkatan Kekuatan Smash Dalam Permainan Bola Voli dapat meningkatkan kemampuan pukulaan smash pada bola voli.
\end{abstract}

Kata Kunci : Latihan Push Up, Kekuatan Smash 


\section{PENDAHULUAN}

Bola voli merupakan suatu permainan beregu yang dimainkan oleh dua tim yang saling berhadapan dan masingmasing terdiri dari enam pemain. Permainan bola voli sangat terkenal di masyarakat, dimulai dari kalangan atas sampai kalangan bawah sudah tidak asing lagi dengan nama permainan bola voli. Sering dijumpai di daerah daerah tertentu permainan bola voli ini dimainkan oleh banyak orang, muda maupun dewasa. Kebanyakan orang memainkan bola voli ini untuk mengisi waktu luang, mencari keringat, dan bahkan untuk prestasi yang meringankan mereka untuk melanjutkan belajar ke jenjang pendidikan yang lebih tinggi.

Bola voli menjadi cabang olahraga permainan yang menyenangkan karena dapat beradaptasi dengan kondisi yang mungkin timbul di dalamnya, dapat dimainkan dengan jumlah pemain yang bervariasi seperti voli pantai dengan jumlah pemain 2 orang, dan permainan dengan jumlah 6 orang yang biasa sering digunakan. Olahraga bola voli dapat dimainkan disegala bentuk lapangan seperti rumput, kayu, pasir, ataupun lantai buatan, serta dapat dilakukan di gedung.

Beberapa peran penting dalam bermainan bolavoli yaitu, tosser (setter), spiker (smash), defender (pemain bertahan) dan libero, peran Tosser adalah pemain yang ditugaskan untuk mengoper bola pada teman satu timnya dan juga untuk mengatur ritme jalannya pertandingan, smasher tugasnya memukul bola sekeras-kerasnya agar jatuh di tempat lawan dan menjadi poin, libero berperan sebagai pemain yang bertahan juga bebas keluar dan masuk lapangan untuk mengganti peranan pemain belakang saja, libero tidak dibolehkan memukul bola atau melakukan semash, hanya diperbolehkan pasing atas dan pasing bawah saja, defender adalah pemain bertahan yang berada dibelakang garis serang yang menerima serangan-serangan lawan yang lolos dari block pemain depan.

Permainan bolavoli tidak lepas dari teknik permainan, maka dari itu pemain harus menguasai beberapa tekhnik dasar bolavoli seperti passing, service, smash dan bloking. Passing adalah teknik untuk mengumpan bola pada teman atau penerimaan bola dari lawan. Service adalah sebuah tindakan awal untuk memulai permainan service juga bisa jadi serangan pertama jika menggunakan service mematikan seperti jump serve full spin. Smash adalah serangan yang dilakukan dari dekat jaring dan dibelakang garis serang, blocking adalah menghalangi datangnya arah bola dari lawan yang melakukan smash.

Seiring berkembangnya permainan bola voli sekarang ini banyak pertandinganpertandingan bola voli untuk mencari pemain-pemain yang handal dalam bermain bola voli yang jika dibina akan menjadi atlet profesional. Adanya pembinaan tidak hanya dilakukan di wilayah daerah saja namun di lembaga-lembaga pendidikan baik di Sekolah Dasar (SD), Sekolah Menengah Pertama (SMP), Sekolah Menengah Atas (SMA), Sekolah Menengah Kejuruan (SMK), maupun di Perguruan Tinggi Negeri/Swasta (PTN/PTS).

Tujuan diadakannya pembinaan ini adalah sebagai wadah penyaluran bakat anakanak yang masih dalam usia muda atau pertumbuhan, yaitu pada anak yang masih duduk di bangku Sekolah Dasar (SD) ataupun Sekolah Menengah Pertama (SMP). Dengan memperkenalkan permainan bola voli sejak awal diharapkan anak mampu memahami, mempelajari, dan memainkan permainan bola voli dengan baik. Apalagi dimulai dari sekolah dasar yang mayoritas siswanya senang untuk bergerak ataupun bermain diharapkan dapat menjadikan siswa mudah untuk belajar bola voli. Untuk dapat memainkan permainan bola voli bagi anakanak usia muda tidaklah mudah. Butuh waktu dan proses yang panjang agar keterampilan gerakan anak dalam bermain bola voli dapat dikuasai dengan baik. Hal ini dikarenakan permainan bola voli merupakan permainan yang menuntut adanya kecepatan, kelentukan, dan kelincahan bagi pemain sendiri. 
Ekstrakulikuler merupakan kegiatan yang dilaksanakan di luar jam pelajaran sekolah. Tujuan diadakannya ekstrakulikuler yaitu untuk memperluas wawasan serta peningkatan dan penerapan nilai-nilai pengetahuan dan kemampuan dalam berbagai hal, seperti olahraga dan seni. Selain itu, ekstrakulikuler juga merupakan salah satu cara menampung dan mengembangkan potensi siswa yang tidak tersalurkan saat di sekolah. Salah satu upaya pembinaan yang diselenggarakan di lingkungan sekolah adalah dengan mengadakan ekstrakulikuler.

Dalam ekstrakulikuler tersebut lebih ditekankan untuk berprestasi dengan peningkatan keterampilan siswa dan dengan latihan-latihan yang sesuai dengan olahraga yang diminati. Hal ini sangat penting agar pembibitan dan pembinaan. olahraga di kalangan siswa akan terus meningkat dan mencapai hasil yang maksimal. Seiring berkembangnya permainan bola voli sekarang ini banyak pertandinganpertandingan bola voli untuk mencari pemain-pemain yang handal dalam bermain bola voli yang jika dibina akan menjadi atlet profesional yang memiliki nilai jual yang tinggi. Adanya pembinaan tidak hanya dilakukan di wilayah daerah saja namun di sekolah juga diadakan pembinaan prestasi bola voli melalui ekstrakulikuler di luar jam belajar. Dalam ekstrakulikuler ini tentu saja siswa diarahkan agar berprestasi sebagai bekal terjun ke masyarakat.

Dengan adanya latihan yang efektif dan efisien diharapkan siswa dapat berkembang lebih cepat dalam melakukan smash agar dapat bersaing dengan sekolah lain dalam pertandingan antar sekolah. Salah satu latihan smash yang baik adalah dengan latihan memukul bola digantung. Latihan tersebut dapat digunakan pelatih untuk melatih atlet bola voli agar hasil smash dapat maksimal. Pada saat melakukan smash in tidak hanya diperlukan tenaga besar saja, melainkan didukung oleh kecepatan untuk mendukung kekuatan pada saat melakukan smash. Latihan push up adalah salah satu latihan untuk meningkatkan ketepatan smash siswa ekstrakurikuler volavoli

\section{METODOLOGI PENELITIAN}

Jenis penelitian ini peneliti
menggunakan studi literatur yaitu
mengumpulkan data atau karya tulis ilmiah
yang berkaitan dengan objek penelitian atau
pengumpulan data yang bersifat kepustakaan, atau telaah yang dilaksanakan untuk memecahkan masalah yang pada dasarnya tertumpu pada penelaahan kritis dan mendalam terhadap bahan-bahan pustaka yang relevan.

Menurut Amir Hamzah secara metodologis kepustakaan tergolong dalam jenis penelitian kualitatif, yaitu prosedur penelitian yang menghasilkan data berupa ucapan atau tulisan dan prilaku orang-orang yang diamati dalam suatu konteks tertentu dan holistik. Dalam konteks kepustakaan, maka data-data diambil dari eksplorasi bahan-bahan pustaka dikaji secara holistik, kemudian dianalisis berdasarkan kerangka berfikir atau teori tertentu/paradigma filosofis yang melandasinya, kemudian menggunakan pendekatan tertentu sesuai tujuan penelitian.

Menurut Mestika Zed riset pustaka tidak sekedar urusan membaca dan mencatat literatur atau buku-buku sebagaimana yang sering dipahami banyak orang selama ini, yang disebut riset kepustakaan atau sering juga disebut studi pustaka ialah serangkaian kegiatan yang berkenaan dengan metode pengumpulan data pustaka, membaca dan mencatat serta mengolah bahan penelitian.

Menurut Suarifqi Diantama studi literature dilakukan dengan cara mempelajari dan mengkaji buku-buku atau sumber informasi tentang masalah yang diteliti, teknik ini selain digunakan untuk melengkapi serta memperkuat hasil penelitian yang dilakukan, teknik ini dilakukan dengan cara mengumpulkan berbagai macam sumber dan literature buku- 
buku yang berkaitan dengan masalah yang sedang diteliti. ${ }^{1}$

\section{HASIL DAN PEMBAHASAN}

Pada bab ini akan dijelaskan Berdasarkan hasil penelitian data A1 peneliti membahas bahwa hasil pengujian hipotesis Uji-t 1) Ada pengaruh latihan push up standar denganthitung (4.38) > ttabel (1.73) taraf nyata $\alpha 0.05$. 2) Ada pengaruh latihan clapping push up dengan thitung (6.18) > ttabel (1.73) taraf nyata $\alpha 0.05$. Kesimpulan penelitian ini adalah : 1) Ada pengaruh latihan push up standar terhadap ketepatan smashbolavoli. 2) Ada pengaruh latihan clapping push up terhadap ketepatan smash bolavoli. 3) latihan clapping push up lebih berpengaruh terhadap ketepatan smash siswa ekstrakurikuler bolavoli.

Berdasarkan hasil penelitian data A2 peneliti membahas bahwa hasil tes kekuatan otot lengan (Push Up) pada Siswa Ekstrakurikuler, bahwa kekuatan otot lengan dalam kategori Cukup yaitu dengan rata-rata 13,46. Dan yang memperoleh norma tes di kategori baik sekali sebanyak 7 orang, berkategori baik sebanyak 3 orang, berkategori cukup sebanyak 4 orang, berkategori kurang sebanyak 4 orang dan yang mendapat nilai berkategori sangat kurang sebanyak 6 orang. Nilai tertinggi adalah 21 dan nilai terendah adalah 4.kekuatan otot lengan didapat hasil $\mathrm{X}^{2}$ adalah 7,5 sedangkan $\mathrm{x}^{2}$ tabel 35,415 yang berati ditribusi normal. Sedangkan tingkat keterampilan smash ekstrakurikuler memiliki tingkat keterampilan smash pada kategori baik yaitu dengan rata-rata 18,33 dan yang memperoleh norma tes di kategori baik sekali sebanyak 10 orang, berkategori baik sebanyak 4 orang, berkategori cukup sebanyak 10 orang, berkategori kurang sebanyak 0 orang dan yang mendapat nilai berkategori sangat kurang sebanyak 0 orang. Nilai tertinggi adalah 28 dan nilai terendah

\footnotetext{
${ }^{1}$ Suarifqi Dintam,M.Pd Metodo Penelitian Pendidikan ( Bandung Pustaka Rahmat, Tahun 2018) Hal. 34
}

adalah 12.kekuatan otot lengan didapat hasil $\mathrm{X}^{2}$ adalah 9 sedangkan $\mathrm{x}^{2}$ tabel 35,415 yang berati ditribusi normal.

Hasil uji homogenitas mendapatkan hasil Fhitung adalah 1,34 dan Ftabel adalah 2,00. Berarti Fhitung 1,34< dari Ftabel 2,00 maka data distribusi homogen. Sedangkan hubungan antara kekuatan otot lengan terhadap keterampilan smash bola voli berdasarkan uji korelasi product moment dengan simpangan antara tes push up dengan keterampilan smash siswa ekstrakurikuler adalah 0,85 pada posisi katagori sangat kuat. Sedangkan nilai ttabel ditentukan berdasarkan tingkat signifikansi $(\alpha)$ adalah 5\% yang digunakan dan derajat kebebasan (d.f = n-2 ) yang besarnya sampel (n) adalah 24, maka d.f $=24-2=22$ berdasarkan distribusi ttabel diperoleh 2,07. Keputusan diambil dengan jalan membandingkan nilai thitung dengan ttabel. Jika thitung lebih kecil dari ttabel, maka keputusan menerima hipotesis Ho. Dan sebaliknya jika thitung lebih besar dari ttabel maka menolak Ho dan menerima Ha, pada pengujian ini , thitung adalah 7,62 lebih besar dari pada ttabel adalah 2,07 maka keputusan menolak hipotesis nol (Ho) dan menerima hipotesis alternatif (Ha).

Maka kesimpulannya adalah terdapat korelasi antara variabel $\mathrm{x}$ dan variabel $\mathrm{y}$. Yaitu terdapat hubungan antara kekuatan otot lengan terhadap keterampilan smash bola voli Kontribusi kekuatan otot lengan terhadap keterampilan smash bola voli adalah sebesar 73\%. Dengan ditemukannya kontribusi yang signifikan dari kekuatan otot lengan terhadap keterampilan smash bola voli, maka kekuatan otot lengan dapat dijadikan sebagai alat untuk memprediksi keterampilan smash bola voli. Smash adalah suatu tindakan memukul bola dengan keras menggunakan teknik tertentu agar bola bisa memasuki lapangan lawan main dengan harapan tidak bisa dibendung oleh regu lain sebagai lawan dalam permainan, sehingga bisa meraih nilai. Menurut Ahmadi smash adalah pukulan bola yang keras dari atas ke bawah dan menukik ke dalam lapangan lawan. Smash atau pukulan keras disebut juga spike merupakan 
bentuk serangan yang paling banyak dipergunakan dalam upaya memperoleh nilai oleh suatu tim. Hasil penelitian membuktikan bahwa terdapat kontribusi kekuatan otot lengan terhadap keterampilan smash bola voli pada Siswa Ekstrakurikuler adalah sebesar $35 \%$.

Berdasarkan hasil penelitian data A3 peneliti membahas Hasil perhitungan uji $t$ dimana $\mathrm{t}$ hitung $=16,55$ diperoleh $\mathrm{t}$ table $=$ 2,201, Karena t hitung lebih besar dari pada $t$ tabel atau $16,55>2,201$ pada taraf signifikansi $5 \%$, dengan derajat perbedaan (d.b) $=\mathrm{N}-1: 12-1=11$, maka hipotesis Nol (H0) yang menyatakan tidak ada pengaruh ditolak sehingga (hipotesis alternative) diterima. Dengan demikian hipotesis yang menyatakan "Ada pengaruh yang signifikan antara latihan push-up terhadap ketepatan smash dalam permainan bola voli pada club sigma palu." Diterima Materi latihan push up dapat berpengaruh terhadap ketepatan smsah dalam permainan bola voli, karena materi latihan yang diberikan pada pelaksanaan penelitiaan memenuhi atau sesuai dengan prinsip-prinsip latihan. Prinsip latihan yang harus diperhatikan dalam melakukan latihan olahraga adalah sebagai berikut.
1. Kontinyu
2. Dosis latihan harus sesuai kemampuan atlet
3. Beban makin lama makin bertambah
4. Variasi latihan
5. Pemanasan
6. Pendinginan

\section{SIMPULAN}

Berdasarkan hasil analisis dan pembahasan yang sudah diuraikan dalam BAB IV maka penulis menyimpulkan sebagai berikut :

1. Data A1 menyimpulkan ada pengaruh latihan push-up standar terhadap keakuratan smash siswa pada permainan bola voli

2. Data A2 menyimpulkan tingkat kekuatan otot lengan pada siswa ekstrakurikuler memiliki tingkat kekuatan otot lengan pada kategori cukup yaitu dengan rata-rata 13,46 dan tingkat keterampilan smash siswa ekstrakurikuler memiliki tingkat keterampilan smash pada kategori baik yaitu dengan rata-rata 18,33.

3. Data A3 menyimpulkan bahwa latihan push- up dapat meningkatkan ketepatan smash pada pemain bola voli Club Sigma Palu. Materi latihan push -up dapat berpengaruh terhadap ketepatan smsah dalam permainan bola voli, karena materi latihan yang diberikan pada pelaksanaan penelitiaan memenuhi atau sesuai dengan prinsip-prinsip latihan.

4. Data A4 menyimpulkan terdapat kontribusi yang signifikan latihan Push-Up Terhadap Ketepatan Hasil Smash Bola Voli Siswa Putra Ekstrakurikuler SMK Negeri 1 Sosa Kabupaten Padang Lawas Tahun 2015.

\section{DAFTAR PUSTAKA}

Abraham. (2012). Pengaruh Latihan Pull Up Dan Latihan Push Up Terhadap Kemampuan Panjat Tebing Kategori Speed Pada Mahasiswa Unm. Jurnal Competitor, Nomor 1 Tahun 4, Pebruari 2012.

Ade Riska Purnama. (2012). Pengaruh Bermain Bola Pantul Terhadap Kemampuan Dasar Passing Bawah Peserta Ekstrakurikuler Bolavoli Putra Di Sma N 7 Yogyakarta. Skripsi. Yogyakarta: UNY.

Ari Murti, Nastiti. (2015). Pengaruh Latihan Passing Bawah Dengan Dinding Dan Berpasangan Terhadap Ketepatan Passing Bawah Dalam Permainan Bolavoli. Skripsi. Semarang: Universitas Negeri Semarang.

Arifin (2015). Pengaruh Push-Up Dengan Tembok Dan Push-Up Dengan Bangku Terhadap Passing Atas Bola Voli Siswa Putra Peserta Ekstrakurikuler SMP 
Negeri 2 Pleret Bantul Tahun Ajaran 2014/2015.

Arikunto, Suharsimi. (2013). Prosedur Penelitian: Suatu Pendekatan Praktik. Bandung: Rineka Cipta.

Bayu Dwi Andriatno. (2016). Peningkatan Hasil Belajar Passing Atas Bolavoli Dengan Alat Bantu Bola Gantung Pada Siswa Kelas Xi Ipa 4 Sma Al Islam 1 Surakarta Tahun Pelajaran 2015/2016.

Beutelstahl, Dieter. (2015). Belajar Bermain Bola Volley. Bandung: Pionir Jaya

Ferdinan Munanda. (2016). Perbandingan Pengaruh Latihan Clap Push-Up Dan
Latihan Triangle Push-Up Terhadap Daya Ledak Otot Lengan Siswa Putra Kelas Vii Smp Negeri 20 Kota Bandar Lampung

Imawati, dkk. (2014). Upaya Meningkatan Keterampilan Passing Atas Dalam Permainan Bola Voli Dengan Bermain Baring Duduk Pada Siswa Kelas V Sd Negeri 04 Nanga Pinoh.

Kuswantono. (2013). Meningkatkan Hasil Belajar Passing Atas Bola Voli Melalui Permainan Volsal Pada Siswa Kelas V Sd Negeri Cablikan Kecamatan Reban Kabupaten Batang Tahun Pelajaran 2012/2013. Skripsi.: UNES. 